\title{
Determinants of Graduate Students’ Usage of Online Social Media as a Job Searching Tool: The Changing Landscape of Labor Market in Bangladesh
}

\author{
Md. Rakibul Hasan ${ }^{1}$, Masnoon Salehin ${ }^{2 *}$ and Mohammad Tariqul Islam ${ }^{1}$
}

${ }^{1}$ Department of Management Information Systems, University of Dhaka, Bangladesh

${ }^{2 *}$ Department of Human Resource Management, Independent University, Bashundhara R/A, Dhaka, Bangladesh

\begin{abstract}
The purpose of this original work is to find the determining factors affecting graduate students' usage of online social media (e.g., Facebook) as a job searching tool. Based on rigorous literature review three latent variables (i.e., graduate students' perception about Facebook as effective for professional networking, their Facebook usage pattern, and job recruiter's responsiveness on their Facebook pages) are hypothesized to have significant positive impact on Facebook usage as a job searching tool. Covariance-based Structural Equation Modeling (CB-SEM) followed by Confirmatory Factor Analysis (CFA) is applied to analyze data from 200 respondents incorporated into 13 observed variables and to get the concluding remarks regarding the hypothesized relationships. All of three latent variables are found to have significant positive impact on the dependent latent construct. Findings are also bearing great importance for the HR policy makers in terms of addressing the issue of how to deal with online social media during recruitment process.
\end{abstract}

Keywords: Online social media; Job searching; Graduate student; Bangladesh

\section{Introduction}

Based on the data of 238 countries, Hootsuite, "We are Social", and Global Social Media Agency (some popular and worldwide social media data management platforms) have released their $6^{\text {th }}$ annual report of Digital in 2017: Global Overview containing some remarkable information about the worldwide usage of online social media (i.e., Facebook, Twitter, LinkedIn, Pinterest, etc.). According to this report $50 \%$ of the world population is now connected to the internet in 2017 which was $40 \%$ in 2016 [1]. Moreover, number of online social media (OSM) users is increased by $21 \%$ which is now 2.8 billion throughout the world among which $91 \%$ are accessing by their mobile devices (e.g., smartphones) [1]. More remarkably, this gigantic connectivity among the users is ensuring spontaneous interactions and immediate conversations among those users. Findings from a study based on the demographic characteristics of the social media users indicated that people from every walk-of-life are using OSM [2] whereas the most popular social medium is Facebook with 1.59 billion of people $[3,4]$.

However, it is well-known to us that OSM is also termed as Online Social Networks (OSN), Social Networking Sites (SNS), Social Networking Web (SNW), Social Media, or Online Community, etc. These theoretical terms are conveying the same meaning and functional characteristics. But in general, Kaplan \& Haenlein [5] has defined OSM as an Web 2.0 tool (more advanced feature of World Wide Web services) which is facilitating the sharing and uploading of user generated contents (e.g., photos, video clips, etc.) by the user themselves. On the other hand, more functional definition of OSM is provied by Boyd \& Ellison [6] as a platform of creating public profile, making connections with others and managing these connections.

Based on the above facts, it can be generalized that even students throughout the world are not beyond the reach of online social networking sites. Recent survey results are indicating that $43.6 \%$ of the total number of social media users throughout the world are from the age group of 24-35 among which $17.8 \%$ are graduated from different institutions $[7,8]$. More interstingly, $50 \%$ users belonging to the age group of 18-24 years old are used to check their online profile when they woke up in the morning, whereas most of them are affiliated with an academic institution [8].
In most of the cases, the purpose of using OSM is for entertainment [9], but in some of the social networking sites like LinkedIn, people (more precisely graduate students) are joining for searching appropriate jobs and maintaining professional relationships [10]. Moreover, social media can be used for various professional reasons comprising of self branding, promotion or impression management [11]. From a study it was found that more than $50 \%$ of the jobseekers in UK use social media for searching any employment opportunity [12]. Another survey on 30,000 graduates conducted by Potentialpark [13] reveals that $48 \%$ graduates prefer to find their potential employers through social media. That is why online community sites are being popular among the jobseekers of "Generation Y" for providing increased opportunities to get connected with a wide-range of professionals, alumni groups, corporate icons and experts $[14,15]$.

On the other hand, employers and recruiters are also relying on the OSM for optimizing their selection process [16-18]. According to Salmen [19] companies can ensure remarkable efficiency in their selection and recruitment process by using social networking sites. Moreover, $92 \%$ of the companies in USA have presence in social media among which $93 \%, 66 \%$ and $54 \%$ are in LinkedIn, Facebook and Twitter respectively [19]. During the selection process, recruiters from the renowned MNCs (Multinational Companies) intend to rely on potential candidates' online profile for screening purposes [20,21]

Because of that, four things about social media postings by the potential employees are emphasized to be careful about, these are:

(1) Inappropriate or vulger photos.

*Corresponding author: Masnoon Salehin, Department of Human Resource Management, Independent University, Bashundhara R/A, Dhaka, Bangladesh, Tel: +01770252294, E-mail: masnoons@yahoo.com

Received April 5, 2018; Accepted May 04, 2018; Published May 10, 2018

Citation: Hasan MR, Salehin M, Islam MT (2018) Determinants of Graduate Students' Usage of Online Social Media as a Job Searching Tool: The Changing Landscape of Labor Market in Bangladesh. Review Pub Administration Manag 6: 245. doi:10.4172/2315-7844.1000245

Copyright: () 2018 Hasan MR, et al. This is an open-access article distributed under the terms of the Creative Commons Attribution License, which permits unrestricted use, distribution, and reproduction in any medium, provided the original author and source are credited. 
Citation: Hasan MR, Salehin M, Islam MT (2018) Determinants of Graduate Students' Usage of Online Social Media as a Job Searching Tool: The Changing Landscape of Labor Market in Bangladesh. Review Pub Administration Manag 6: 245. doi:10.4172/2315-7844.1000245

Page 2 of 7

(2) Abusive contents.

(3) Bad comments about former employer or collegues, and

(4) Poor communication skill $[22,23]$.

Two studies on 175 and 148 job applicants, consequitively, revealed that Big Five Personality characteristics (i.e., openness, conscientiousness, extroversion, and neuroticism) could be predicted based on their social media activities, which became useful for their employers in recruiting and evaluating their candidates whether they were going to be professionaly sound or not $[24,25]$.

Now lets take a look into the current situation of online social media usage in Bangladesh, because the concentrated context of this research initiative is Bangladesh consisting of its graduate students (job seekers or employees) from different public universities and their social media usage pattern for seeking job, those are the subjects of futher investigation and exploration. From a recent survey of 2016, it is found that the most widely used online media in Bangladesh is Facebook having 22 million active users which is $1.1 \%$ of the total number of users across the globe and the rank is 2 [1]. That is the significance of this study to find out the usage pattern of Facebook rather than any other OSM (i.e., Twitter, LinkedIn, etc.) for job searching purposes by the graduates in Bangladesh which has direct effect on the behavior of supply of labor in Bangladesh. According Boswell, Zimmerman, \& Swider [26] there are three situations whenever a job seeker searches for job, these are - (1) after completing graduation, (2) during a job for reemployment purpose, or (3) after lossing a job. Here, the situation after completing graduation is taken into consideration, because of its significance as a first job opportunity in anyone's life.

\section{Proposed framework, hypotheses, and accompanied literature}

From the above discussion and based on the realization of the importance of OSM from the perspectives of job seekers and job recruiters following objective is set to fulfill through this explorative study.

- Identifying the most determining factors stimulating graduate students' usage of Facebook for job searching purpose in Bangladesh.

In consistent with the above objective, a theoretical framework is proposed by the authors which is subject to empirical testing and validation. Figure 1 represents the framework of this study.

Hypotheses of this study are as the followings:

Hypothesis 1 (H1): Responsiveness and presence of the recruiters in Facebook positively affect graduate students' job seeking activity on their Facebook profile.

Hypothesis 2 (H2): Graduate students' perception about Facebook as a networking platform with the professionals/alumni/recruiters positively influence their job searching activity in Facebook.

Hypothesis 3 (H3): Graduate students' Facebook usage pattern positively influence their job searching activity in Facebook.

There are few literary works found addressed the challenge of finding appropriate determining factors of why graduate students are using online social media (Facebook, in the context of this study) as a job searching tool. Findings from the relevant research papers are depicted in the following paragraphs with respect to the operational definitions of the latent constructs and the importance of the hypothesized relations of this study (Figure 1).

\section{Responsiveness of the recruiters $\rightarrow$ Usage of facebook as a job searching tool}

As it is believed by the authors that there is a bilateral relationships behind the activity of using Facebook as a job searching tool by the graduate students. Recruiters respond and post job placement opportunities and job seekers will search and get the opprtunity in

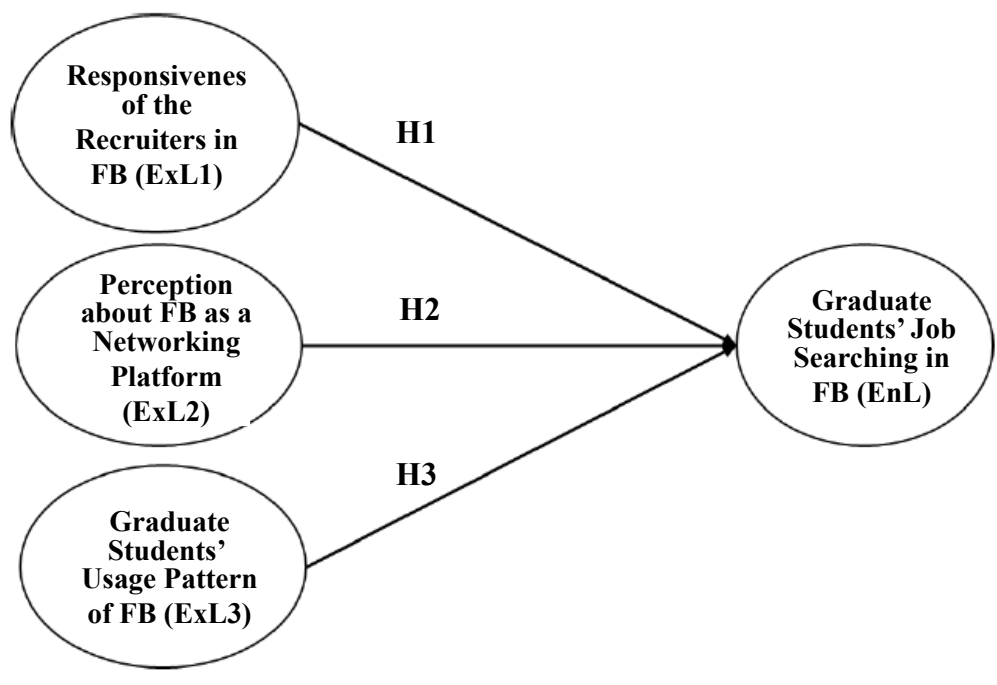

Figure 1: Theoretical framework of the study. 
OSM. This bilateral relation and common preference of the recruiters and job seekers is proved by a study of Nikolaou [14]. He has exposed a great insight about the job search activity in OSM by two types of job seekers (active and passive job seekers), whereas the job seekers and recruiters prefer professionally oriented OSM (e.g., LinkedIn) rather than nonprofessionally oriented OSM (e.g., Facebook) [14]. Hence, social networks and other online informal communities are eradicating information asymmetry between the job seekers and recruiters through bringing them closer to each other [27,28]. According to Burke \& Kraut [29] network with strong social ties among them based on proper responsiveness of the recruiters can reduce the stress of getting job, increase the opportunity of social support, maximize the perceived effectiveness of Facebook as a job searching tool [11].

\section{Perceiving facebook as effective for searching job $\rightarrow$ Usage of facebook as a job searching tool}

However, along with the responsiveness of the recruiters, perceived effectiveness of social media as a job searching tool is found to have significant effect on the career-oriented self-disclosure activity of the job seekers on OSM [11]. Nevertheless, fairness of the selection process in OSM is also emphasized and found to have moderating effect on this relationship in another study [30].

Graduate students' usage pattern of facebook $\rightarrow$ Usage of facebook as a job searching tool

Nikolaou [14] has measured the preference of selecting OSM for searching job opportunities by the job seekers in terms of their social media usage pattern (i.e., spent time, frequency of visit in OSM, etc.). In a study, Buettne [31] has used UTAUT model (Unified Theory of Acceptance and Use of Technology) developed by Venkatesh, Morris, Davis et al. [32] to explain the behavioral intention of the job seekers to use OSM in terms of the explanatory constructs of performance expectancy, effort expectancy, social influence, facilating conditions, hedonic motivation, price value, and habit. The necessity to have enough resources (i.e., smartphone, computer, internet connection, access to social media, etc.), termed as facilitating condition in UTAUT model, and social media browsing habit of the job seekers are found statistically significant on that study as the determinants of using OSM for job seeking [31]. Table 1 represents the summary of previous literary works relevent to the study.

\section{Methods}

\section{Target population, sampling, and sample size}

Target population of this study are the students those are graduated from different public and private universities in Bangladesh during the academic session of 2016-17 and seeking employment opportunity according to their individual career interest. Sampling frame (i.e., list of job-seeking graduate students) for this study were selected at different levels of clustering. At the first level, Southeast University (private university) and University of Dhaka (public university) were selected from the two clusters of public and private universities. At the second level, 200 (100 from Southeast University and 100 from University of Dhaka) sample units (i.e., job seeking graduate students) were randomly selected and brought under empirical investigation from the different clusters of students representing diverse academic backgrounds of social science, pure science, engineering, and business studies.

\section{Data collection and preparation}

A structured questionnaire (See Appendix 1) based survey was conducted to collect required information from the respondents, whereas the questionnaire consists of 13 items representing the observed variables of 3 constructs (unobserved variables). 215 questionnaires were disseminated and interviewed by the data collectors, and 15 respondents were removed from further analysis because of erroneous responses.

\section{Data analysis tool}

Covariance-based Structural Equation Modeling (CB-SEM) tool followed Confirmatory Factor Analysis (CFA) are applied to estimate the loadings of the observed variables to their respective unobserved variables and the hypothesized causal relations (Figure 1) among the constructs (aka. Unobserved or Latent Variable).

\section{Results and Interpretations}

Figure 2 contains the path values or estimated parameters of corresponding hypothesized measurement and structural models in a diagrammatic format. These path values are representing the factor weights among the constructs and observed variables, regression weights among the constructs, variances of the error terms and constructs, and covariances among the observed variables.

Table 2 containing the summary of the model is representing the overall validity of the model, whereas the $\chi^{2}$ test statistic is applied to test null hypothesis of $\Sigma=\Sigma(\theta)$ (there is no different between sample covariance matrix and population covariance matrix) [33]. Large value of $\chi^{2}$ test statistic with the probability value $>0.001$ denotes the validity of the estimated 33 parameters on this model.

Outcomes regarding the significance level and critical ratio corresponding to each of the estimated parameters (i.e., regression

\begin{tabular}{|c|c|c|c|}
\hline Title and Author & Hypotheses & Methods & Findings \\
\hline \multirow[b]{2}{*}{$\begin{array}{l}\text { Social networking web sites in job search and } \\
\text { employee recruitment (Nikolaou, 2014) }\end{array}$} & $\begin{array}{l}\text { Job seekers prefer job oriented social networking sites } \\
\text { (i.e., Linkedln) rather than general SNS (i.e., Facebook) }\end{array}$ & Paired sample t-test & $\begin{array}{l}\text { Significant } \\
(t=6.99)\end{array}$ \\
\hline & $\begin{array}{c}\text { Recruiters also prefer job oriented SNS rather than } \\
\text { general SNS. }\end{array}$ & Paired sample t-test & $\begin{array}{l}\text { Significant } \\
(\mathrm{t}=7.79)\end{array}$ \\
\hline $\begin{array}{l}\text { Getting a job via career oriented social networking } \\
\text { sites: the weakness of ties (Buettner, 2016) }\end{array}$ & $\begin{array}{l}\text { Performance expectancy, effort expectancy, social } \\
\text { influence, facilitating conditions, hedonic motivation, } \\
\text { price value, and habit have positive impact on the } \\
\text { behavioral intention to use OSM for securing job. }\end{array}$ & $\begin{array}{l}\text { Structural equation } \\
\text { modeling }\end{array}$ & $\begin{array}{l}\text { Facilitating conditions and habit } \\
\text { were found significant with the } \\
\text { coefficients of } 0.600 \text { and } 0.362 \text {, } \\
\text { respectively }\end{array}$ \\
\hline $\begin{array}{l}\text { Predictors of job seekers' self-disclosure on social } \\
\text { media (Quirdi, Segers, Quirdi, \& Pais, 2015) }\end{array}$ & $\begin{array}{l}\text { OSM effectiveness in searching job has positive impact } \\
\text { on self-disclosure of the job seekers }\end{array}$ & $\begin{array}{l}\text { Structural equation } \\
\text { modeling }\end{array}$ & Significant $(\beta=0.08)$ \\
\hline $\begin{array}{l}\text { Using social media websites as selection tools: } \\
\text { the role selection process fairness and job pursuit } \\
\text { intention (Madera, 2012) }\end{array}$ & $\begin{array}{l}\text { Perceiving social networking websites as selection tool } \\
\text { has impact on the intention of pursuing job }\end{array}$ & $\begin{array}{l}\text { Structural equation } \\
\text { modeling }\end{array}$ & $\begin{array}{l}\text { Significant (path coefficient is } \\
0.26 \text { ) }\end{array}$ \\
\hline
\end{tabular}

Table 1: Findings and methodologies of previous studies. 


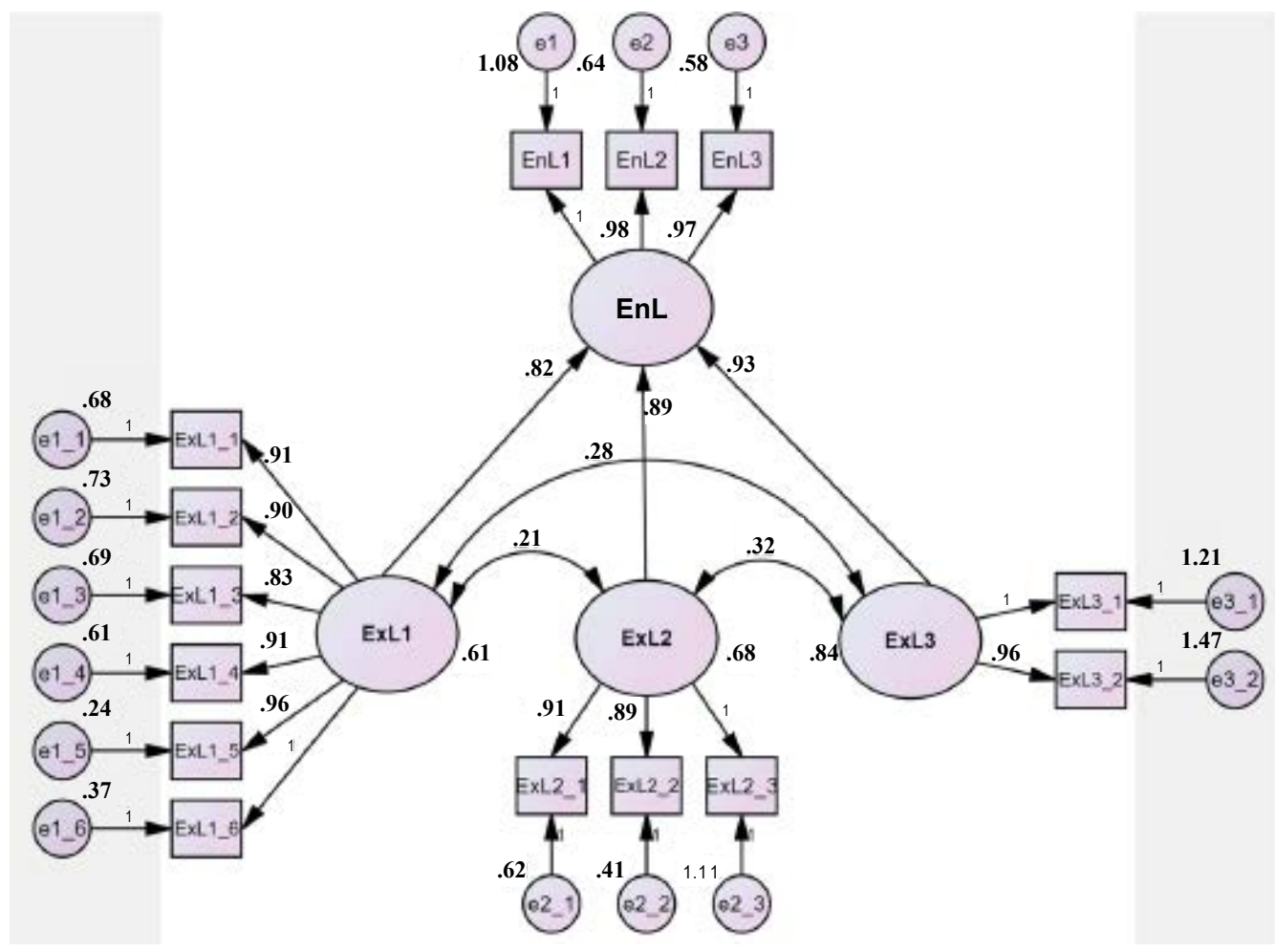

Figure 2: AMOS path diagram of hypothesized measurement and structural models.

\begin{tabular}{|c|}
\hline Computation of degrees of freedom (Default model) \\
\hline $\begin{array}{c}\text { Number of distinct sample moments: } 105 \\
\text { Number of distinct parameters to be estimated: } 33 \\
\text { Degrees of freedom (105-33): } 72\end{array}$ \\
Result (Default model) \\
\hline Chi-square $=257.376$ \\
Degrees of freedom $=72$ \\
Probability level= 0.008 \\
\hline
\end{tabular}

Table 2: AMOS output of model summary.

weights, variances, and covariances) are presented in Tables 3-6. According to Byrne and Kline [33,34] critical value $>1.96$ and probability value $<0.000$ are considred statistically sound and significant. Modification Indices (MI) and Parameter Change (Par Change) values in Tables 7 and 8 test the effect size of the fixed parameters and address the issue of what would be happened to the hypothesized model if these fixed parameters (values set to 1 prior analysis) were freely estimated [33]. MI values $>10$ (Tables 9-12) will trigger the necessity to conduct post-hoc analysis and re-assess the hypothesized model for incorporating associated path or error terms not as fixed parameters $[33,35]$.

Tables 9-11 contain the goodness-of-fit index values of the model. According to the Table 11, Normal Fit Index (NFI), Relative Fit Index (RFI), Incremental Fit Index (IFI), Tucker-Lewis Index (TLI), Comparative Fit Index (CFI), Root Mean Square Error of Approximation (RMSEA), Closeness of Fit (PCLOSE), Expected Cross-validation Index (ECVI), and Modified ECVI (MECVI), all are expressing the well fit of the model to the data set and the minimum discrepancy between sample and population.

\begin{tabular}{|c|c|c|c|c|c|}
\hline \multicolumn{2}{|c|}{ Model parameters } & \multirow{2}{*}{$\begin{array}{c}\text { Estimate } \\
0.925\end{array}$} & \multirow{2}{*}{$\begin{array}{c}\text { S.E. } \\
0.089\end{array}$} & \multirow{2}{*}{$\begin{array}{c}\text { C.R. } \\
10.393\end{array}$} & \multirow{2}{*}{$\begin{array}{c}\mathbf{P} \\
* * *\end{array}$} \\
\hline EnL & $\leftarrow \operatorname{ExL} 1$ & & & & \\
\hline EnL & $\leftarrow$ ExL2 & 0.891 & 0.082 & 10.866 & $* * *$ \\
\hline EnL & $\leftarrow \operatorname{ExL3}$ & 0.935 & 0.087 & 10.747 & *** \\
\hline ExL1_6 & $\leftarrow \operatorname{ExL} 1$ & \multicolumn{4}{|c|}{1.000} \\
\hline ExL1_5 & $\leftarrow \operatorname{ExL} 1$ & 0.961 & 0.108 & 8.898 & *** \\
\hline ExL1_4 & $\leftarrow \operatorname{ExL} 1$ & 0.915 & 0.093 & 9.839 & $* * *$ \\
\hline ExL1_3 & $\leftarrow \operatorname{ExL} 1$ & 0.834 & 0.096 & 8.688 & *** \\
\hline ExL1_2 & $\leftarrow \operatorname{ExL} 1$ & 0.907 & 0.085 & 10.671 & *** \\
\hline ExL1_1 & $\leftarrow \operatorname{ExL} 1$ & 0.916 & 0.079 & 11.595 & *** \\
\hline ExL2_3 & $\leftarrow$ ExL2 & \multicolumn{4}{|c|}{1.000} \\
\hline ExL2_2 & $\leftarrow$ ExL2 & 0.893 & 0.113 & 7.903 & *** \\
\hline ExL2_1 & $\leftarrow$ ExL2 & 0.943 & 0.110 & 8.573 & *** \\
\hline ExL3_1 & $\leftarrow$ ExL3 & \multicolumn{4}{|c|}{1.000} \\
\hline ExL3_2 & $\leftarrow \operatorname{ExL3}$ & 0.963 & 0.076 & 12.671 & *** \\
\hline EnL1 & $\leftarrow \mathrm{EnL}$ & \multicolumn{4}{|c|}{1.000} \\
\hline EnL2 & $\leftarrow E n L$ & 0.983 & 0.089 & 11.045 & *** \\
\hline EnL3 & $\leftarrow \mathrm{EnL}$ & 0.978 & 0.116 & 8.431 & *** \\
\hline
\end{tabular}

Table 3: AMOS output of model parameters (Factor loadings or Regression weights).

\section{Overall Findings regarding the hypotheses of structural model}

Based on the above analysis it can be concluded that graduate student' perception about the effectiveness of Facebook as a job searching tool, recruiter's responsiveness on their Facebook pages, and students' Facebook usage pattern are the statistically significant determinants 
Citation: Hasan MR, Salehin M, Islam MT (2018) Determinants of Graduate Students' Usage of Online Social Media as a Job Searching Tool: The Changing Landscape of Labor Market in Bangladesh. Review Pub Administration Manag 6: 245. doi:10.4172/2315-7844.1000245

Page 5 of 7

\begin{tabular}{|c|c|c|c|c|c|}
\hline \multicolumn{2}{|c|}{ Model parameters } & Estimate & S.E. & CR. & $\mathbf{P}$ \\
\hline ExL1 & $\leftarrow$ ExL2 & 0.216 & 0.033 & 6.545 & *** \\
\hline ExL2 & $\leftarrow$ ExL3 & 0.324 & 0.036 & 9.000 & *** \\
\hline ExL1 & $\leftarrow$ ExL3 & 0.282 & 0.037 & 7.622 & *** \\
\hline
\end{tabular}

Table 4: AMOS output of model parameters (Covariances).

\begin{tabular}{|c|c|c|}
\hline \multicolumn{2}{|c|}{ Model parameters } & Estimate \\
\hline ExL1 & <--> ExL2 & 0.439 \\
\hline ExL2 & <--> ExL3 & 0.398 \\
\hline ExL1 & <--> ExL3 & 0.155 \\
\hline
\end{tabular}

Table 5: AMOS output of model parameters (Correlations among the constructs).

\begin{tabular}{|c|c|c|c|c|}
\hline Model parameters & Estimate & S.E. & CR. & P \\
\hline ExL1 & 0.612 & 0.091 & 5.649 & $* * *$ \\
\hline ExL2 & 0.685 & 0.061 & 11.229 & $* * *$ \\
\hline ExL3 & 0.842 & 0.065 & 11.954 & $* * *$ \\
\hline el_6 & 0.376 & 0.056 & 6.711 & $* * *$ \\
\hline el_5 & 0.249 & 0.060 & 4.167 & $* * *$ \\
\hline el_4 & 0.612 & 0.064 & 9.537 & $* * *$ \\
\hline el_3 & 0.699 & 0.072 & 9.707 & $* * *$ \\
\hline el_2 & 0.738 & 0.077 & 9.626 & $* * *$ \\
\hline el_1 & 0.680 & 0.072 & 9.406 & $* * *$ \\
\hline e2_3 & 1.117 & 0.112 & 9.974 & $* * *$ \\
\hline e2_2 & 0.411 & 0.056 & 7.311 & $* * *$ \\
\hline e2_1 & 0.624 & 0.075 & 8.301 & $* * *$ \\
\hline e3_1 & 1.210 & 0.154 & 7.857 & $* * *$ \\
\hline e3_2 & 1.477 & 0.275 & 5.366 & $* * *$ \\
\hline el & 1.083 & 0.126 & 8.590 & $* * *$ \\
\hline e2 & 0.646 & 0.076 & 8.549 & $* * *$ \\
\hline e3 & 0.587 & 0.079 & 7.460 & $* * *$ \\
\hline
\end{tabular}

Table 6: AMOS output of model parameters (Variances).

\begin{tabular}{|c|c|c|c|}
\hline \multicolumn{2}{|c|}{ Model fit } & M.I. & Par Change \\
\hline E1 & <--> e2 & 3.311 & 0.273 \\
\hline e2_1 & <--> e2 & 3.764 & -0.213 \\
\hline e2_2 & $<-->$ e2_1 & 4.950 & 0.139 \\
\hline e1_1 & <-> ExL2 & 5.678 & 0.003 \\
\hline e1_1 & <--> e2 & 5.737 & 0.122 \\
\hline e1_1 & $<-->$ e2_1 & 8.571 & 0.148 \\
\hline e1_2 & <-> ExL2 & 4.071 & 0.002 \\
\hline e1_2 & <--> e3 & 4.030 & -0.105 \\
\hline e1_2 & <-> e2_2 & 5.376 & 0.102 \\
\hline e1_2 & <--> e1_1 & 6.431 & 0.310 \\
\hline e1_3 & <-> ExL2 & 5.299 & 0.002 \\
\hline e1_3 & <--> e2 & 6.238 & 0.127 \\
\hline e1_3 & <--> e2_1 & 5.883 & 0.123 \\
\hline e1_3 & <-> e1_1 & 4.094 & 0.190 \\
\hline e1_4 & <--> e3_1 & 4.041 & -0.179 \\
\hline e1_4 & <--> e1_3 & 3.457 & 0.221 \\
\hline e1_5 & <--> e3 & 6.512 & 0.103 \\
\hline e1_5 & $<-->$ e1_2 & 6.920 & -0.108 \\
\hline e1_5 & <--> e1_3 & 6.419 & -0.101 \\
\hline e1_6 & <-> ExL2 & 7.995 & -0.002 \\
\hline e1_6 & <--> e1 & 7.246 & -0.145 \\
\hline e1_6 & <--> e1_1 & 8.685 & -0.122 \\
\hline e1_6 & $<-->$ e1_2 & 4.471 & -0.090 \\
\hline e1_6 & <--> e1_3 & 7.010 & -0.110 \\
\hline e1_6 & <--> e1_5 & 5.032 & 0.099 \\
\hline
\end{tabular}

Table 7: AMOS output of model fit (Modification indices of Regression weights).

\begin{tabular}{|c|c|c|c|}
\hline \multicolumn{2}{|c|}{ Model fit } & M.I. & Par Change \\
\hline EnL2 & <--- EnL1 & 8.346 & 0.165 \\
\hline EnL2 & <--- ExL2_1 & 9.225 & 0.184 \\
\hline EnL2 & <--- ExL1_1 & 7.418 & 0.175 \\
\hline EnL2 & <--- ExL1_3 & 7.856 & 0.189 \\
\hline EnLI & <--- EnL2 & 6.221 & 0.273 \\
\hline EnLI & <--- ExL1_6 & 5.731 & -0.198 \\
\hline ExL2_1 & <--- EnL2 & 8.231 & -0.220 \\
\hline ExL2_1 & $<---$ ExL2_2 & 4.854 & 0.149 \\
\hline ExL2_1 & <--- ExL1_1 & 8.335 & 0.185 \\
\hline ExL2_1 & <--- ExL1_3 & 6.342 & 0.169 \\
\hline ExL2_2 & $<---$ ExL2_1 & 6.324 & 0.128 \\
\hline ExL1_1 & <--- ExL3 & 5.500 & 0.180 \\
\hline ExL1_1 & <--- ExL2 & 8.403 & 0.309 \\
\hline ExL1_1 & $<---E n L$ & 9.035 & 0.333 \\
\hline ExL1_1 & $<---$ EnL2 & 7.483 & 0.212 \\
\hline ExL1_1 & $<---$ EnL1 & 6.969 & 0.128 \\
\hline ExL1_1 & <--- ExL2_1 & 8.953 & 0.225 \\
\hline ExL1_1 & <--- ExL1_2 & 8.254 & 0.347 \\
\hline ExL1_1 & <--- ExL1_3 & 7.128 & 0.234 \\
\hline ExL1_2 & <--- ExL2_2 & 6.449 & 0.177 \\
\hline ExL1_2 & <--- ExL1_1 & 6.318 & 0.339 \\
\hline ExL1_3 & <-- EnL & 4.564 & 0.225 \\
\hline ExL1_3 & $<---E n L 2$ & 8.931 & 0.188 \\
\hline ExL1_3 & <--- ExL2_1 & 8.086 & 0.171 \\
\hline ExL1_3 & <--- ExL1_1 & 5.466 & 0.207 \\
\hline
\end{tabular}

Table 8: AMOS output of model fit (Modification indices of Covariances).

\begin{tabular}{|c|c|c|c|c|c|}
\hline Model & NFI Delta1 & RFI rho1 & IFI Delta2 & TLI rho2 & CFI \\
\hline Default model & 0.950 & 0.998 & 0.971 & 0.937 & 0.912 \\
\hline Saturated model & 1.000 & 0.000 & 1.000 & 0.000 & 1.000 \\
\hline $\begin{array}{c}\text { Independence } \\
\text { model }\end{array}$ & 0.000 & 0.000 & 0.000 & 0.000 & 0.000 \\
\hline
\end{tabular}

Table 9: AMOS output of model fit (Baseline comparison).

\begin{tabular}{|c|c|c|c|c|}
\hline Model & RMSEA & LO90 & HI90 & PCLOSE \\
\hline Default model & 0.021 & 0.050 & 0.100 & 0.670 \\
\hline Independence model & 0.189 & 0.176 & 0.201 & 0.000 \\
\hline
\end{tabular}

Table 10: AMOS output of model fit (Root mean square error of approximation).

\begin{tabular}{|c|c|c|c|c|}
\hline Model & ECVI & LO90 & HI90 & MECVI \\
\hline Default model & 1.012 & 1.001 & 1.890 & 1.101 \\
\hline Saturated model & 1.055 & 1.055 & 1.055 & 1.141 \\
\hline Independence model & 3.836 & 3.421 & 4.290 & 3.848 \\
\hline
\end{tabular}

Table 11: AMOS output of model fit (Expected cross-validation index).

\begin{tabular}{|c|c|c|c|}
\hline $\begin{array}{c}\text { Factor loadings/ } \\
\text { Regression weights }\end{array}$ & $>\mathbf{0 . 8 0}$ & $\begin{array}{c}\text { Modification } \\
\text { indices }\end{array}$ & $<\mathbf{1 0 . 0}$ \\
\hline C.R. (Critical Ratio) & $>+/-1.96$ & NFI, CFI & $>0.90$ \\
\hline Covariances & $\begin{array}{c}<1.0 \text { and Non- } \\
\text { negative }\end{array}$ & RFI, IFI & $>0.95$ \\
\hline Variances & Non-Negative & ECVI & $\begin{array}{c}\text { Value (Default Model) } \\
<\text { Saturated and } \\
\text { Independent Model }\end{array}$ \\
\hline RMSEA & $<0.05$ & MECVI & Same as ECVI \\
\hline TLI & Value close to 0.95 & Correlation & $<1.0$ \\
\hline PCLOSE & & $>0.50$ & \\
\hline
\end{tabular}

Table 12: Acceptable threshold values of estimated parameters and goodness-offit indices [33,34,35,37,38]. 
Citation: Hasan MR, Salehin M, Islam MT (2018) Determinants of Graduate Students' Usage of Online Social Media as a Job Searching Tool: The Changing Landscape of Labor Market in Bangladesh. Review Pub Administration Manag 6: 245. doi:10.4172/2315-7844.1000245

Page 6 of 7

\section{Hypotheses}

Status

Hypothesis 1 (H1): Responsiveness and presence of the recruiters in Facebook positively affect graduate students' job seeking activity on their Facebook profile. Hypothesis $2(\mathrm{H} 2)$ : Graduate students' perception about Facebook as a networking platform with the professionals/alumni/recruiters positively influence their job searching activity in Facebook.

Hypothesis $3(\mathrm{H} 3)$ : Graduate students' Facebook usage pattern positively influence their job searching activity in Facebook.

Table 13: Hypothesis of the study.

\begin{tabular}{|c|c|c|c|}
\hline Latent constructs & & Observed variable & Measurement scale \\
\hline \multirow{6}{*}{$\begin{array}{l}\text { Responsiveness and Presence of } \\
\text { the Recruiters in Facebook (ExL1) }\end{array}$} & ExL1.1 & $\begin{array}{l}\text { Employers/professionals/recruit ers post job openings in } \\
\text { Facebook }\end{array}$ & $\begin{array}{l}\text { 5-point Likert Scale (1: Strongly Disagree...5: } \\
\text { Strongly Agree) }\end{array}$ \\
\hline & ExL1.2 & $\begin{array}{l}\text { Employers/professionals/recruit ers responds in Facebook } \\
\text { regarding the post }\end{array}$ & $\begin{array}{c}\text { 5-point Likert Scale (1: Strongly Disagree...5: } \\
\text { Strongly Agree) }\end{array}$ \\
\hline & ExL1. 3 & Jobsites related FB pages post job openings in Facebook & $\begin{array}{l}\text { 5-point Likert Scale (1: Strongly Disagree...5: } \\
\text { Strongly Agree) }\end{array}$ \\
\hline & ExL1.4 & Jobsites respond in Facebook regarding the post & $\begin{array}{c}\text { 5-point Likert Scale (1: Strongly Disagree...5: } \\
\text { Strongly Agree) }\end{array}$ \\
\hline & ExL1.5 & Alumni post job openings in Facebook & $\begin{array}{c}\text { 5-point Likert Scale (1: Strongly Disagree...5: } \\
\text { Strongly Agree) }\end{array}$ \\
\hline & ExL1.6 & Alumni respond in Facebook regarding the post & $\begin{array}{c}\text { 5-point Likert Scale (1: Strongly Disagree...5: } \\
\text { Strongly Agree) }\end{array}$ \\
\hline \multirow{3}{*}{$\begin{array}{l}\text { Graduate Students Perception } \\
\text { about Facebook as a Networking } \\
\text { Platform with the Professionals or } \\
\text { Recruiters (ExL2) }\end{array}$} & ExL2.1 & $\begin{array}{l}\text { Facebook work as networking media with professionals/ } \\
\text { employers/faculti es/alumni }\end{array}$ & $\begin{array}{l}\text { 5-point Likert Scale (1: Strongly Disagree...5: } \\
\text { Strongly Agree) }\end{array}$ \\
\hline & ExL2.2 & $\begin{array}{l}\text { I think that such networks with } \\
\text { professionals/employers/faculti es/alumni in Facebook helps to } \\
\text { get job related information }\end{array}$ & $\begin{array}{l}\text { 5-point Likert Scale (1: Strongly Disagree...5: } \\
\text { Strongly Agree) }\end{array}$ \\
\hline & ExL2.3 & $\begin{array}{l}\text { And, I also think that such networks with professionals/ } \\
\text { employers/faculti es/alumni in Facebook helps to get the } \\
\text { intended job. }\end{array}$ & $\begin{array}{c}\text { 5-point Likert Scale (1: Strongly Disagree...5: } \\
\text { Strongly Agree) }\end{array}$ \\
\hline \multirow{2}{*}{$\begin{array}{l}\text { Graduate Students' Facebook } \\
\text { Usage Pattern (ExL3) }\end{array}$} & ExL3.1 & Time spent on Facebook per day User & $\begin{array}{c}\text { 5-point Likert Scale (1: Extremely Light User.... 5: } \\
\text { Extremely Heavy User) }\end{array}$ \\
\hline & ExL3.2 & Frequency of visiting and exploring own profile in a day & $\begin{array}{c}\text { 5-point Likert Scale (1: Least Frequent...... 5: Most } \\
\text { Frequent) }\end{array}$ \\
\hline
\end{tabular}

Table 14: Questionnaire items.

of using Facebook as a job searching tool by the graduate students in Bangladesh. The concluding remarks regarding the hypotheses of this study are as the followings (Table 13).

\section{Discussion}

The findings of this study can contribute to the re-designing process of human resource policy of any organization through incorporating the significant role of Online Social Media Sites in recruitment function. Recruiters can think and act according to the needs of job seekers by knowing the factors determining the usage of OSM for job seeking purposes. A new dimension of labor market supply side was being unveiled throughout this investigative exploratory study. Moreover, academic institutions, HR consultants, and other training and development institutes can re-assess their curriculum for incorporating the findings of this study.

Nevertheless, there is also a limitation of this study. Demographic diversity of the respondents was not incorporated on the study. The findings might not be generalized for the students graduated from an academic institution residing outside Dhaka city. On the other hand, respondents institutional and social-status diversity may have moderating effect on the hypothesized model which can be an issue of conducting further research.

\section{Conclusion}

However, the significance of online social media in job searching and advertising is undeniable. Furthermore, OSM are also being a bless for the job seekers with physical disabilities [36-38]. The quest to know what factors are determining the usage of OSM for job searching purposes by the graduate students is fulfilled in this explorative study, which will be very definitive for the HR administrators. Different questionnaire items also mentioned (Table 14).

\section{References}

1. Kemp S (2017) Digital in 2017: Global overview.

2. Perrin A (2015) Social media usage: 2005-2015, Pew Research Center.

3. Kerby J (2016) Here's how many people are on facebook, instagram, twitter and other big social networks.

4. Bicen H, Cavus N (2011) Social network sites usage habits of undergraduate students: Case study of Facebook. Procedia. Soc Behav Sci 28: 943-947.

5. Kaplan AM, Haenlein M (2010) Users of the world, unite! The challenges and opportunities of social media. Bus Horizons 53: 59-68.

6. Boyd DM, Ellison NB (2007) Social network sites: Definition, history and scholarship. J Comput Media Comm 1: 210-230.

7. Zephoria Digital Marketing (2017) The top 20 valuable facebook statistics, zephoria insight.

8. Chaffey D (2017) Global social media research summary 2018, smart insights.

9. Lin KY, Lu HP (2011) Why people use social networking sites: An empirical study integrating network externalities and motivation theory. Comput Hum Behav 27: 1152-1161.

10. Stopfer JM, Gosling SD (2013) Online social networks in the work context. In the psychology of digital media at work 1: 39-59.

11. Quirdi ME, Segers J, Ouirdi AE, Pais I (2015) Predictors of job seekers' selfdisclosure on social media. Comput Hum Behav 53: 1-12.

12. Nigel Wright Recruitment (2011) The impact of social media on recruitment.

13. Potentialpark (2011) Talent interaction: Does facebook beat linkedin? 
Citation: Hasan MR, Salehin M, Islam MT (2018) Determinants of Graduate Students' Usage of Online Social Media as a Job Searching Tool: The Changing Landscape of Labor Market in Bangladesh. Review Pub Administration Manag 6: 245. doi:10.4172/2315-7844.1000245

14. Nikolaou I (2014) Social networking web sites in job search. Int J Sel Ass 22: 179-189.

15. Manroop L, Richardson J (2013) Using social media for job search: Evidence from generation y job seekers. J Soc Media Hum Resour Manage 12: 167-180.

16. Beimborn D (2017) Centre of human resources information systems Information systems in services.

17. Grasz J (2009) Forty-five percent of employers use social networking sites to research job candidates, careerbuilder survey finds.

18. Roulin N, Bangerter A (2013) Social networking websites in personne selection: A signaling perspective on recruiters' and applicants' perceptions. J Pers Psychol 12: 143-151.

19. Salmen S (2012) What's next-the next trends: Recruiting in the social web. Göttingen: Business Village $\mathrm{GmbH}$.

20. Jobvite (2013) Social recruiting survey results 2013.

21. Broughton A, Foley B, Ledermaier S, Cox A (2013) The use of social media in the recruitment process. Brighton, UK: Institute for Employment Studies.

22. Betances D, Solarczyk R, Bellows C (2012) Personal social networking: Affects on companies hiring decisions. pp: 1-22.

23. Vicknair J, Elkersh D, Yancey K, Budden MC (2010) The use of social networking websites as a recruiting tool for employee. Ame J Bus Edu.

24. Stoughton JW, Thompson LF, Meade AW (2013) Big five personality traits reflected in job applicants' social media postings. Cyberpsychol Behav Soc Network 16: 800-805

25. Bohnert D, Ross WH (2010) The Influence of social networking web sites on the evaluation of job candidates. Cyberpsychol Behav Soc Netw 13: 341-349.

26. Boswell WR, Zimmerman RD, Swider BW (2012) Employee job search: Toward an understanding of search context and search objectives. J Manage 38: 129-163.

27. Cingano F, Rosolia A (2012) People I know: Job search and social networks. J Labor Econ 30: 291-332.
28. Slovensky R, Ross WH (2012) Should human resource managers use socia media to screen job applicants? Managerial and legal issues in the USA. info 14: $55-69$.

29. Burke M, Kraut R (2013) Using facebook after losing a job: Differential benefits of strong and weak ties. Social networks during major transitions (Personal and Political) 1: 1419-1429.

30. Madera JM (2012) Using social networking websites as a selection tool: The role of selection process fairness and job pursuit intentions. Int $\mathrm{J}$ Hosp Manage 31: 1276-1282.

31. Buettne R (2016) Getting a job via career-oriented social networking sites: The weakness of ties. 2016 49th Hawaii International conference on system sciences, Hawaii: IEEE 1: 2156-2165.

32. Venkatesh V, Morris MG, Davis GB, Davis FD (2003) User acceptance of information technology: toward a unified view. MIS Quart 27: 425-478.

33. Byrne BM (2010) Structural equation modeling with AMOS: Basic concepts applications, and programming ( $\left.2^{\text {nd }} E d n\right)$. New York: Routledge 1: $365-367$.

34. Kline RB (2011) Principles and practice of structural equation modeling ( $3^{\text {rd }}$ Edn) New York: The Guilford Press. Multidiscip J Struct Equ Model 19: 509-512.

35. Malhotra NK (2014) Marketing research: An applied orientation. New York Pearson Education.

36. Duersch J (2013) A comparison of social media job search versus traditional job search methods on employment of students with moderate to severe disabilities. All Graduate Teses and Dissertations, Paper 2009, 45: 1-3.

37. Hair JF, Hult GTM, Ringle CM, Sarstedt M (2014) A primer on partial least squares structural equation modeling (PLS-SEM). SAGE Publications, Inc. 46 184-185.

38. Little TD (2013) The Oxford handbook of quantitative methods in psychology London: Oxford University Press. 